\title{
Association Between Low Testosterone and Graft Dysfunction Early After Heart Transplantation: results from cross-sectional study
}

\author{
Poglajen $\mathbf{G}^{1}$, Jensterle $\mathbf{M}^{2}$, Janez $A^{2}$, Haddad $F^{3}$, Vrtovec $B^{1}$ \\ 1Department of Cardiology, University Medical Centre Ljubljana \\ ${ }^{1}$ Department of Endocrinology, Diabetes and Metabolic Diseases, University Medical Centre Ljubljana \\ ${ }^{3}$ Cardiovascular Institute, Stanford University School of Medicine, Stanford, CA, USA
}

\section{OBJECTIVES}

An inverse relation was found between testosterone and vasculopathy of the allograft in heart transplanted men. We evaluated the correlation between serum testosterone levels and graft function early after heart transplantation.

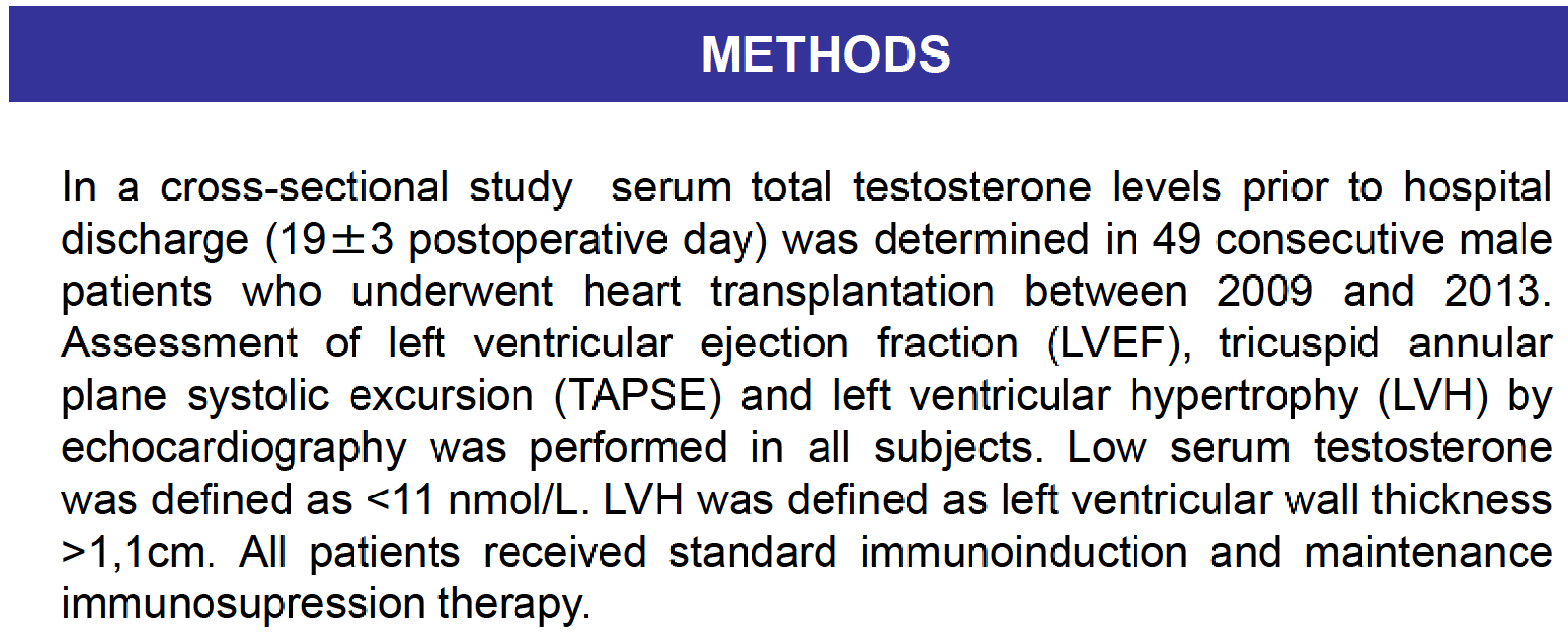

\section{METHODS}

\section{RESULTS}

Low testosterone was present in 21 (43\%) (Group A), and normal in 27 (57\%) patients (Group B). The prevalence of osteoporosis was signifitancly higher in Group A compared to Group B ( $90 \%$ vs $60 \%, p=0.02)$. The two groups did not differ in age (58.7 \pm 7.2 years in Group A vs. $54.3 \pm 11.9$ years in Group B), the presence of renal dysfunction, arterial hypertension, diabetes or hyperlipidemia, time of hospital discharge, donor age and allograft ischemic time. Both groups had comparable mean tacrolimus through levels, dose of mycophenolate and metylprednisolone. However, before discharge, patients in Group A had significantly lower LVEF $(60 \pm 4.8 \%$ vs. $63.3 \pm 5.8 \%$ vs. Group $B, P=0.04)$ and TAPSE $(1.3 \pm 0.3 \mathrm{~cm}$ vs. $1.6 \pm 0.3 \mathrm{~cm}$ in Group $B, P=0.03)$. The prevalence of $\mathrm{LVH}$ did not differ between the two groups. Before discharge, more patients in Group $A$ were found to have low grade rejection ( $15 \%$ vs. $0 \%$ in Group $B ; P=0.03$ ).

\section{CONCLUSIONS}

Low testosterone appear to be associated with inferior graft function and increased incidence of rejection early after heart transplantation. Immunomodulatory role of testosterone remains to be further elucidated. 